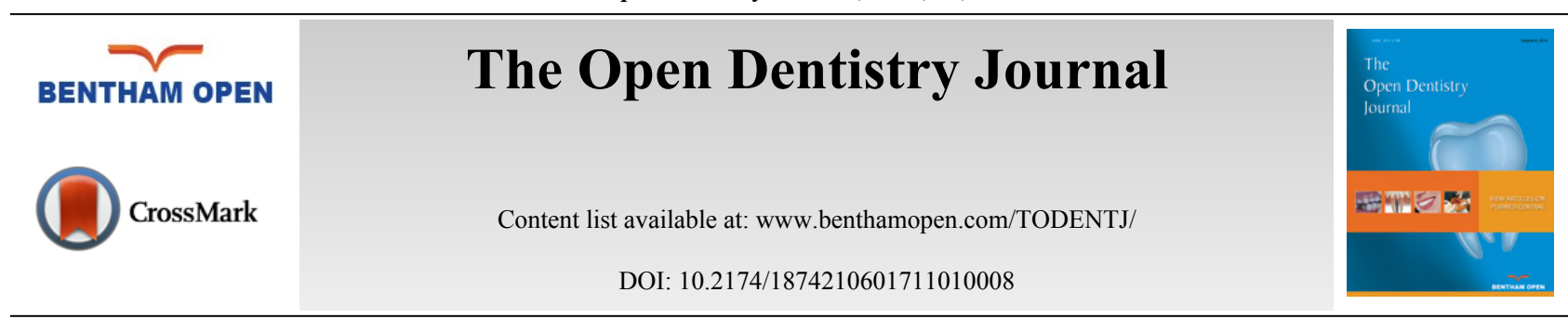

DOI: $10.2174 / 1874210601711010008$

RESEARCH ARTICLE

\title{
Alveolar Bone Fracture: Pathognomonic Sign for Clinical Diagnosis
}

\author{
Zvi Gutmacher ${ }^{1}$, Eli Peled ${ }^{2,3}$, Doron Norman ${ }^{2,3}$ and Shaul Lin ${ }^{3,4, *}$ \\ ${ }^{I}$ Department of Maxillofacial Rehabilitation, Rambam Health Care Campus, Haifa, Israel \\ ${ }^{2}$ Department of Orthopedic Surgery B, Rambam Health Care Campus, Haifa, Israel \\ ${ }^{3}$ The Bruce Rappaport Faculty of Medicine, Technion-Israel Institute of Technology, Haifa, Israel \\ ${ }^{4}$ Endodontic and Dental Trauma Department, Rambam Health Care Campus, Haifa, Israel
}

Received: August 23, 2016

Revised: December 28, 2016

Accepted: January 08, 2017

\begin{abstract}
:
Aim:

Dental injuries, especially luxation and avulsion, are common. Dental trauma can cause alveolar bone fracture that can lead to tooth loss and malocclusion. Single tooth alveolar bone fractures are difficult to identify unless it protrudes through the overlying mucosa and can be visualized. Pain, malocclusion, and tooth mobility provide signs of suspected alveolar bone fractures. Integrity of the proximate alveolar bone should be examined for fractures where avulsion, luxation, or other tooth trauma is detected. Any suggestion of alveolar fractures should be further investigated with an appropriate radiograph.
\end{abstract}

\section{Summary:}

This case report shows a pathognomonic sign that detects and diagnosis single tooth alveolar bone fractures, i.e., a localized hematoma crossing the attached gingiva from the free gingival margin to the vestibular mucosa. This should serve as a warning for localized alveolar bone fracture.

A visualized hematoma and gentle, careful palpation may help detect covered fractures when the overlying mucosa is not perforated.

Keywords: Alveolar bone fracture, Avulsion, Dental trauma, Luxation.

\section{INTRODUCTION}

A traumatic dental injury (TDI), especially luxation and avulsion injuries can cause alveolar bone fractures which in turn can lead to tooth loss. Traumatic alveolar bone fractures can be categorized into two types. The first type is confined to the area surrounding a single tooth. The second type can be defined as regional, and is generally easier to detect since the entire dento-alveolar segment is dislocated. Dentoalveolar traumas involving multiple teeth are not common, and mostly occur after severe trauma events such as serious sport injury, violence, or traffic accident $[1,2]$. The highest prevalence of oral trauma is among children and adolescents during dental and alveolar development [3]. Wright et al. [1] reported a frequency of 16\% of traumatic dental injuries (TDIs) in adolescents in the group of 12- to 15 -years of age. In a 12-year systematic review of the literature regarding prevalence and incidence of TDIs, Glendor [4] stated that TDIs usually affect a single tooth, but can also involve the anterior teeth, and particularly, maxillary incisors. In a study of a 16-year-old cohort in northern Sweden, Borssen \& Holm reported that $75 \%$ of the traumatized teeth were upper incisors [5]. Trauma accounts for $26 \%$ to $76 \%$ of uncomplicated crown fractures (UCF) [6], $15.5 \%$ for complicated crown fractures (CCF) [7], 7.7\% for root fractures [8], 4-22\% for avulsion, $5.5 \%$ for bone alveolar fractures, and 47- 58\% for soft tissue injury [7,9]. Management of concomitant dental injuries may be challenging, especially if there are additional complications related particularly to delayed treatments. Appropriate and timely

\footnotetext{
* Address correspondence to this author at the Endodontic and Dental Trauma Department, Rambam Health Care Campus, POB 9602, Haifa 31096, Israel; Tel: 972-4-8541927; Fax: 972-4-8370752; E-mail: sh_lin@rambam.health.gov.il
} 
diagnosis and interventions, as well as long-term follow-up are crucial for the success of the treatment [6, 10 - 12]. In the maxillary anterior area, regional teeth and alveolar ridge injury can cause severe alveolar ridge deficiency which may result in ridge atrophy, maxillary retrognathism and future rehabilitation difficulties [13]. Loss of teeth and alveolar bone, along with fibrotic scar formation, can cause adverse changes in the inter-arch space, occlusal plane, arch relationship and form. These changes may impede rehabilitation and impact the esthetic outcome [14]. Single tooth alveolar bone fractures are difficult to discern, unless the overlying mucosa is perforated. Symptoms such as pain, malocclusion, and tooth mobility provide additional clues of suspected alveolar bone fractures. Pulpal necrosis may occur following alveolar fractures near the apical root region $[15,16]$. The integrity of the proximate alveolar bone should be examined for fractures in the areas where avulsions, luxations, or other tooth injury are detected [17]. When signs of alveolar fractures are observed, a radiograph of the traumatized region should be taken [18].

The current manuscript - presents a case report describing a particular sign which is pathognomonic for single tooth alveolar bone fractures. An extensive review of relevant medical literature has not revealed similar cases.

\section{CASE DESCRIPTION}

A 12-year old boy presented at the Endodontics and Dental Trauma Unit located in our hospital, due to dental trauma. The medical and dental history was taken, followed by a thorough physical examination, neurological test, extra- and intra-oral examinations, and radiographic examination. The clinical examination showed laceration of the lips, and laterally luxation of the face and of the first right and left maxillary incisors. A localized hematoma crossing the attached gingiva from the free gingival margin to the vestibular mucosa was observed, adjacent to the left maxillary incisor (Fig. 1).

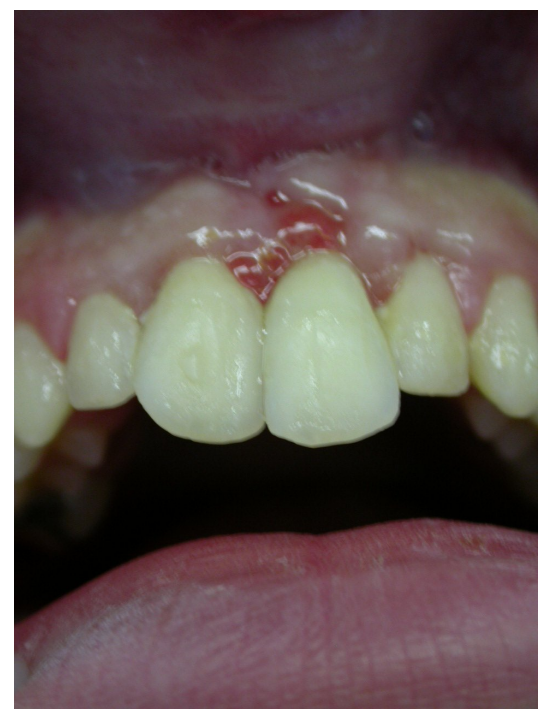

Fig. (1). Localized hematoma crossing the attached gingiva from the free gingival margin to the vestibular mucosa.

A periapical radiograph was taken on the day of injury (Fig. 2). The lacerations of the upper lip were sutured and the teeth manually repositioned. After occlusal adjustment, the teeth were splinted with a semi-flexible splint made with orthodontic wire \#0.012 (ORMCO, Glendora, Mexico) and composite resin, which remained in place for 10 days. Ten days later, during the second appointment, an endodontic access cavity was created on the central left and right maxillary incisors. Canals were chemo-mechanically instrumented and dressed with calcium-hydroxide. At the end of the session, the splint was removed and the occlusion was reassessed. A month later, the canals were prepared to size \#60 and sealed with gutta-percha points and AH26 sealer.

At 16 months of follow-up, no symptoms were observed. A clinical examination showed vertical bone resorption at the fracture area. The radiograph showed remarkable bone resorption around the first left maxillary incisor Figs. (3 and 4). The patient was referred to the Periodontal Department for further evaluation and treatment. 


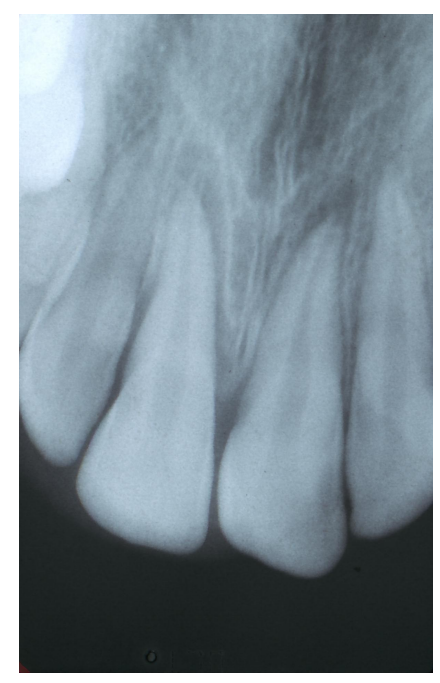

Fig. (2). Diagnostic radiograph taken on the day of injury.

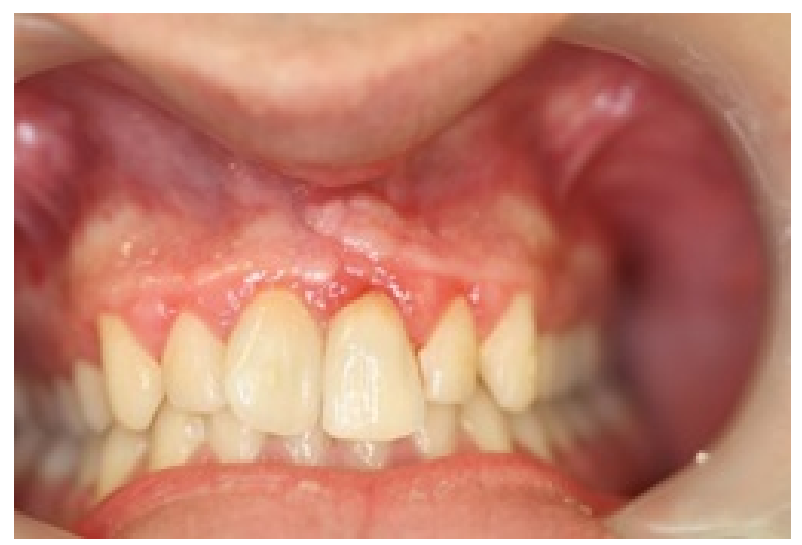

Fig. (3). Follow-up clinical examination shows the vertical bone resorption as the fracture area.

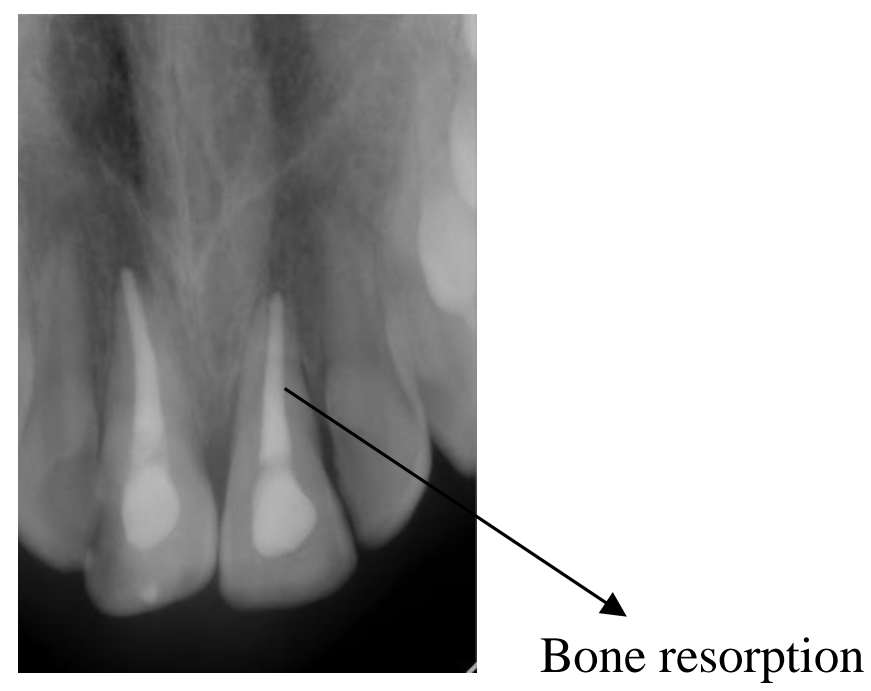

Fig. (4). Radiographic evaluation shows remarkable bone resorption around the first left maxillary incisor.

\section{DISCUSSION}

Long-term consequences of dento-alveolar trauma mismanagement can be devastating. Early correct diagnosis of such injuries and appropriate referral - might greatly contribute to the success of the treatment and can prevent premature tooth or alveolar bone loss, and the consequent burden of prosthetic rehabilitation. In the case described in 
the current paper, the localized hematoma crossing the attached gingiva from the free gingival margin to the vestibular mucosa was a warning sign for a localized alveolar bone fracture. In cases of alveolar bone fractures, recent protocols recommend fixation for a period of 4 to 6 weeks $[19,20]$, based on the prognosis of bone healing after injury. However, in this particular case, due to the omitted diagnosis of the alveolar bone fracture, the most appropriate treatment which could have reduced bone resorption had not been provided.

Alveolar bone fractures are usually splinted using wiring techniques, such as arch bars, figure-eight and loop wiring, orthodontic bands, and acrylic or metallic cap splints. In case of luxation injuries, the outcome depends more on the duration of the splinting than on the type of splinting [21]. For example, in a study conducted in animal models, replanted teeth splinted for 30 days developed a higher incidence of replacement resorption than teeth splinted for only one week [22].

In alveolar fractures, the fixation plays an important role in achieving proper fracture and bone healing. Unlike the fixation for avulsion, the fixation for alveolar fractures should be rigid in order to allow proper bone healing. While maintaining a rigid fixation of the alveolar segment, the splint should allow physiological movement of the luxated teeth in the fractured alveolar segment. There are various types of rigid fixation, such as wiring with arch bars, composite splint, plate and screw fixation. The choice of the splinting method depends on the type of alveolar fracture and the number of teeth presented in the arch. The duration of the fixation can vary between 4 to 6 weeks. The key to adequate immobilization is to anchor the fracture segment rigidly to at least 3 to 4 stable teeth on both sides of the fractured alveolar segment $[23,24]$. The incidence of alveolar fractures is difficult to estimate since they are usually reported in conjunction with dental injuries and facial fractures.

For instance, in a study conducted at the University Dental Hospital in Copenhagen, alveolar fractures accounted for $9 \%$ of all dento-alveolar injuries of permanent dentition [25, 26]. Another retrospective study of 237 patients who suffered from maxillofacial injuries over a five year period, reported that alveolar fractures accounted for approximately $2 \%$ of all mandibular and $9 \%$ of all maxillary fractures [27]. At the Osaka University Dental Hospital, the most common form of maxillofacial injury found among 174 patients up to 16 years of age was mandibular fractures (56\%), followed by dento-alveolar fractures (31\%) [28].

Although alveolar fractures can occur at any age, the first and second decades after the permanent incisors erupt are the most common [26, 28]. A review of 9,543 cases of cranio-maxillo-facial trauma conducted at the University Hospital of Innsbruck found that the mean age of all dento-alveolar injuries was 18 years [29]. Epidemiological studies have shown that males are twice as likely as females to experience dento-alveolar and facial trauma [30].

The causes of alveolar fractures vary within different age groups. Among children, these fractures are frequently caused by bicycle injuries, falls, sports injuries and, occasionally, car crashes and child abuse. For adults, the cause is usually fighting, motor vehicle crashes, falls, contact injuries and, occasionally work-related trauma [28, 29,31].

Alveolar fractures occur predominantly in dentate arches, but can also occur in edentulous arches. The anterior maxilla and mandible are common sites due to the location and vulnerability of these regions [32, 33]. Other factors which predispose the anterior maxilla to dento-alveolar injuries include increased maxillary incisor over-jet and proclination and incompetent lips [34]. The anatomic shape and high density of buccal and lingual cortical bone make the posterior mandible less prone to alveolar fractures [13].

Alveolar fracture may involve an isolated tooth, or two or more teeth with labial or lingual displacement of the dento-alveolar segment, resulting in loss of the arch continuity and painful occlusal interference. In isolated alveolar bone fracture, the detection of such a trauma is very difficult. In the presented case, insufficient management led to an incorrect protocol treatment and unsatisfactory results of the alveolar bone resorption.

Alveolar fractures cause injury to the supporting bone and vascular supply and, potentially, to the pulp, periodontal ligament (PDL) of the involved teeth, and adjacent mucogingival soft tissue. Complications that arise represent a direct result of damage to any of these tissues and can be further exacerbated by inadequate treatment.

Inadequate fixation and splinting can cause mobility of the fractured segment. As a result, small alveolar segments can sequestrate, resulting in the loss of supporting bone, and this can compromise the tooth prognosis. Proper fixation, an adequate immobilization period and elimination of occlusal trauma are necessary for bone healing. In alveolar fractures, tooth loss can occur as a result of severe comminution of the bony socket, fractured and non-restorable roots, or subsequent root resorption, and may have serious psychological implications, especially when anterior teeth are involved $[35,36]$. 
Ekşioğlu et al. investigated the presence of different ultrasonographic findings associated with fractures among 39 patients up to 14 years of age. In all patients, a subperiosteal hematoma was found. A hematoma should raise the suspicion of alveolar fracture and could be considered as a pathognomonic sign of alveolar fracture, especially when it is not detected radiographically [37].

\section{CONCLUSION}

Early recognition of clinical and radiographic signs of localized alveolar bone fracture is essential, and appropriate management is imperative to prevent bone and tooth loss risks. In the 16 years old boy case presented in the current manuscript, recognizing the presence of a hematoma adjacent to the first left maxillary incisor along with careful palpation would have helped to detect the covered alveolar fracture. This, in turn, would have had a positive impact on the treatment outcome, by specifically using the immobilization and splinting method.

\section{CLINICAL SIGNIFICANCE}

The presence of hematoma should be considered pathognomonic for alveolar fracture.

\section{CONFLICT OF INTEREST}

The authors confirm that this article content has no conflict of interest.

\section{ACKNOWLEDGEMENTS}

Declared none.

\section{REFERENCES}

[1] Wright G, Bell A, McGlashan G, Vincent C, Welbury RR. Dentoalveolar trauma in Glasgow: an audit of mechanism and injury. Dent Traumatol 2007; 23(4): 226-31. [http://dx.doi.org/10.1111/j.1600-9657.2006.00430.x] [PMID: 17635356]

[2] Koyuturk AE, Kusgoz A. Multiple dentoalveolar traumatic injury: a case report (3 years follow up). Dent Traumatol 2008; $24(4)$ ) e16-9. [http://dx.doi.org/10.1111/j.1600-9657.2008.00579.x] [PMID: 18557754]

[3] Lam R, Abbott P, Lloyd C, Lloyd C, Kruger E, Tennant M. Dental trauma in an Australian rural centre. Dent Traumatol 2008; 24(6): 663-70. [http://dx.doi.org/10.1111/j.1600-9657.2008.00689.x] [PMID: 19021660]

[4] Glendor U. Epidemiology of traumatic dental injuriesa 12 year review of the literature. Dent Traumatol 2008; 24(6): 603-11. [http://dx.doi.org/10.1111/j.1600-9657.2008.00696.x] [PMID: 19021651]

[5] Borssén E, Holm A-K. Traumatic dental injuries in a cohort of 16-year-olds in northern Sweden. Endod Dent Traumatol 1997; 13(6): 276-80. [http://dx.doi.org/10.1111/j.1600-9657.1997.tb00055.x] [PMID: 9558509]

[6] Olsburgh S, Jacoby T, Krejci I. Crown fractures in the permanent dentition: pulpal and restorative considerations. Dent Traumatol 2002; 18(3): 103-15.

[http://dx.doi.org/10.1034/j.1600-9657.2002.00004.x] [PMID: 12110103]

[7] Calişkan MK, Türkün M. Clinical investigation of traumatic injuries of permanent incisors in Izmir, Turkey. Endod Dent Traumatol 1995; 11(5): 210-3. [http://dx.doi.org/10.1111/j.1600-9657.1995.tb00490.x] [PMID: 8625933]

[8] Majorana A, Pasini S, Bardellini E, Keller E. Clinical and epidemiological study of traumatic root fractures. Dent Traumatol 2002; 18(2): 77-80.

[http://dx.doi.org/10.1034/j.1600-9657.2002.180206.x] [PMID: 12184216]

[9] Bastone EB, Freer TJ, McNamara JR. Epidemiology of dental trauma: a review of the literature. Aust Dent J 2000; $45(1): 2-9$. [http://dx.doi.org/10.1111/j.1834-7819.2000.tb00234.x] [PMID: 10846265]

[10] Flores MT, Andersson L, Andreasen JO, et al. Guidelines for the management of traumatic dental injuries. I. Fractures and luxations of permanent teeth. Dent Traumatol 2007; 23(2): 66-71. [http://dx.doi.org/10.1111/j.1600-9657.2007.00592.x] [PMID: 17367451]

[11] Flores MT, Andersson L, Andreasen JO, et al. Guidelines for the management of traumatic dental injuries. II. Avulsion of permanent teeth. Dent Traumatol 2007; 23(3): 130-6. [http://dx.doi.org/10.1111/j.1600-9657.2007.00605.x] [PMID: 17511833]

[12] Berrezouga L, Kammoun D, Bhouri L, Alaya BT, Belkhir MS. Treatment of multiple traumatized anterior teeth associated with an alveolar bone fracture in a 15-year-old school boy: a 2.5-year follow up. Dent Traumatol 2011; 27(2): 147-51. [http://dx.doi.org/10.1111/j.1600-9657.2010.00967.x] [PMID: 21281442]

[13] Berman LH, Blanco L, Cohen S. Alveolar fractures. In: Berman LH, Blanco L, Cohen S, Eds. A clinical guide to dental traumatology. St. Louis, MO: CV Mosby 2007; pp. 1248-71. 
[14] Zahrani AA. Augmentation in two stages of atrophic alveolar bone prior to dental rehabilitation: a case report. J Contemp Dent Pract 2007; 8(6): 57-63. [PMID: 17846672]

[15] Oikarinen K, Lahti J, Raustia AM. Prognosis of permanent teeth in the line of mandibular fractures. Endod Dent Traumatol 1990; 6(4): 177-82. [http://dx.doi.org/10.1111/j.1600-9657.1990.tb00414.x] [PMID: 1983466]

[16] Kamboozia AH, Punnia-Moorthy A. The fate of teeth in mandibular fracture lines. A clinical and radiographic follow-up study. Int J Oral Maxillofac Surg 1993; 22(2): 97-101.

[http://dx.doi.org/10.1016/S0901-5027(05)80811-2] [PMID: 8320457]

[17] Berman LH, Blanco L, Cohen S. Patient assessment. In: Berman LH, Blanco L, Cohen S, Eds. A clinical guide to dental traumatology. St. Louis, MO: CV Mosby 2007; pp. 12-24.

[18] Cohenca N, Simon JH, Roges R, Morag Y, Malfaz JM. Clinical indications for digital imaging in dento-alveolar trauma. Part 1: traumatic injuries. Dent Traumatol 2007; 23(2): 95-104. [http://dx.doi.org/10.1111/j.1600-9657.2006.00509.x] [PMID: 17367457]

[19] Berman LH, Blanco L, Cohen S. Alveolar fractures. In: Berman LH, Blanco L, Cohen S, Eds. A clinical guide to dental traumatology. St. Louis, MO: CV Mosby 2007; p. 147.

[20] Andreasen JO, Borum MK, Jacobsen HL, Andreasen FM. Replantation of 400 avulsed permanent incisors. 4. Factors related to periodontal ligament healing. Endod Dent Traumatol 1995; 11(2): 76-89. [http://dx.doi.org/10.1111/j.1600-9657.1995.tb00464.x] [PMID: 7641622]

[21] Nasjleti CE, Castelli WA, Caffesse RG. The effects of different splinting times on replantation of teeth in monkeys. Oral Surg Oral Med Oral Pathol 1982; 53(6): 557-66. [http://dx.doi.org/10.1016/0030-4220(82)90340-1] [PMID: 6954434]

[22] Berman LH, Blanco L, Cohen S. A clinical guide to dental traumatology. St. Louis, MO: CV Mosby 2007; pp. 127-48.

[23] Akamine RN. Diagnosis of traumatic injuries of the face and jaws. Oral Surg Oral Med Oral Pathol 1955; 8(4): 349-58. [http://dx.doi.org/10.1016/0030-4220(55)90101-8] [PMID: 14370759]

[24] Ravn JJ. Dental injuries in Copenhagen schoolchildren, school years 19671972. Community Dent Oral Epidemiol 1974; 2 (5): 231-45. [http://dx.doi.org/10.1111/j.1600-0528.1974.tb01658.x] [PMID: 4154162]

[25] Andreasen JO. Classification, etiology and epidemiology. In: Andreasen JO, Ed. Traumatic injuries of the teeth. $3^{\text {rd }}$ ed. Copenhagen: Munksgaard 1994; pp. 217-44.

[26] Motamedi MH. An assessment of maxillofacial fractures: a 5-year study of 237 patients. J Oral Maxillofac Surg 2003; 61(1): 61-4. [http://dx.doi.org/10.1053/joms.2003.50049] [PMID: 12524610]

[27] Iida S, Matsuya T. Paediatric maxillofacial fractures: their aetiological characters and fracture patterns. J Craniomaxillofac Surg 2002; 30(4): $237-41$ [http://dx.doi.org/10.1054/jcms.2002.0295] [PMID: 12231205]

[28] Gassner R, Tuli T, Hächl O, Rudisch A, Ulmer H. Cranio-maxillofacial trauma: a 10 year review of 9,543 cases with 21,067 injuries. J Craniomaxillofac Surg 2003; 31(1): 51-61. [http://dx.doi.org/10.1016/S1010-5182(02)00168-3] [PMID: 12553928]

[29] Lin S, Levin L, Goldman S, Peled M. Dento-alveolar and maxillofacial injuries - a retrospective study from a level 1 trauma center in Israel. Dent Traumatol 2007; 23(3): 155-7. [http://dx.doi.org/10.1111/j.1600-9657.2005.00418.x] [PMID: 17355291]

[30] Lin S, Levin L, Goldman S, Sela G. Dento-alveolar and maxillofacial injuries: a 5-year multi-center study. Part 2: severity and location. Dent Traumatol 2008; 24(1): 56-8.

[http://dx.doi.org/10.1111/j.1600-9657.2006.00511.x] [PMID: 18173667]

[31] Olson RA, Fonseca RJ, Zeitler DL, Osbon DB. Fractures of the mandible: a review of 580 cases. J Oral Maxillofac Surg 1982; 40(1): 23-8. [http://dx.doi.org/10.1016/S0278-2391(82)80011-6] [PMID: 6950035]

[32] Levin L, Friedlander LD, Geiger SB. Dental and oral trauma and mouthguard use during sport activities in Israel. Dent Traumatol 2003; 19(5): 237-42.

[http://dx.doi.org/10.1034/j.1600-9657.2003.00196.x] [PMID: 14708646]

[33] Järvinen S. Incisal overjet and traumatic injuries to upper permanent incisors. A retrospective study. Acta Odontol Scand 1978 ; 36(6): 359-62. [http://dx.doi.org/10.3109/00016357809029088] [PMID: 281861]

[34] Berman CL, Berman LG. The psychological implications of tooth loss. Dent Clin North Am 1969; 13(4): 961-6. [PMID: 5258218]

[35] Davis DM, Fiske J, Scott B, Radford DR. The emotional effects of tooth loss: a preliminary quantitative study. Br Dent J 2000 ; $188(9)$ : 503-6. [PMID: 10859849]

[36] Ekşioğlu F, Altinok D, Uslu MM, Güdemez E. Ultrasonographic findings in pediatric fractures. Turk J Pediatr 2003; 45(2): 136-40. [PMID: 12921301] 
[37] Cohen S, Blanco L, Berman LH. Early radiographic diagnosis of inflammatory root resorption. Gen Dent 2003; 51(3): 235-40. [PMID: 15055707]

(C) Gutmacher et al.; Licensee Bentham Open

This is an open access article licensed under the terms of the Creative Commons Attribution-Non-Commercial 4.0 International Public License (CC BY-NC 4.0) (https://creativecommons.org/licenses/by-nc/4.0/legalcode), which permits unrestricted, non-commercial use, distribution and reproduction in any medium, provided the work is properly cited. 